\title{
NOTĂ PRIVIND UN SUPORT SPECIFIC CULTURII BOIAN, FAZA VIDRA, DESCOPERIT LA SULTANA-GHEŢĂRIE
}

VASILE OPRIȘ, CĂTĂLIN LAZĂR

\author{
NOTE ABOUT A POT STAND SPECIFIC TO BOIAN CULTURE, VIDRA PHASE, \\ DISCOVERED AT SULTANA-GHEṬ̆RIE
}

During the archaeological campaign of 2012 in the area of the Sultana-Ghețărie flat settlement, Mânăstirea commune, Călăraşi County, Romania, an interesting pit (C13) was discovered and researched. That complex belonging to the Boian culture, Vidra phase, was a typical pit for these prehistoric communities. The pit contained different archaeological materials (e.g. sherds, animal bones, flint artefacts etc.). To the bottom of thr pit, 18 fragments of a ceramic stand were found. They were analysed in technological, typological and functional terms. This type of artefact was particular for prehistoric communities from Vidra phase of Boian culture, and we will also discuss the analogies for it, based on other similar finds in Boian sites in Romania.

KEY-WORDS: Eneolithic, Boian culture, Vidra phase, pot stand

CUVINTE CHEIE: eneolitic, cultura Boian, faza Vidra, suport ceramic

\section{INTRODUCERE}

Acest articol prezintă o piesă ceramică specifică comunităților fazei Vidra a culturii Boian, anume un suport de vas de formă paralelipipedică. Această categorie este cunoscută în literatura de specialitate și sub denumirea de „cutii-suport"1 sau „suporturi paralelipipedice", reprezentând o categorie de piese mai puțin studiată de specialişti. Fără a avea o frecvență mare în cadrul diverselor contexte arheologice domestice specifice fazei Vidra a culturii Boian, piesele de acest tip sunt atestate în diverse așezări din România și Bulgaria, atribuite respectivelor comunități umane.

Piesa care face obiectul prezentului articol a fost descoperită în cuprinsul așezării de la Sultana-Ghețărie (jud. Călărași) în anul 2012.

LOCALIZAREA ȘI ISTORICUL SITULUI

Aşezarea de la Sultana-Ghețărie aparține culturii Boian, faza Vidra şi este localizată în partea de sud-est a României, pe malul drept al fostului râu Mostiştea, la cca $7 \mathrm{~km}$ de Dunăre și de granița cu Bulgaria (PI. I/1). Din punct de vedere administrativ, situl ${ }^{3}$ se află pe teritoriul localității Sultana, comuna Mănăstirea, județul Călărași.

Din perspectivă topografică, așezarea de la Sultana-Ghețărie este localizată pe un promontoriu al terasei înalte a lacului Mostiștea, în partea de vest a acesteia (PI. I/2), la $320 \mathrm{~m} \mathrm{( \pm 1}$ $\mathrm{m})$ vest de necropola de la Sultana-Malu Roşu ${ }^{4}$. Coordonatele geografice ale punctului SultanaGhețărie sunt $44^{\circ} 15^{\prime} 37.83072 " \mathrm{~N}$ şi $26^{\circ} 51^{\prime} 47.93720^{\prime \prime} \mathrm{E}$, iar altitudinea absolută a zonei ocupate de

\footnotetext{
${ }^{I}$ Rosetti 1934, 12-14; Berciu 1935, 13; Comșa 1959, 127

${ }^{2}$ Şerbănescu, Şandric 2012, 117

3 Lazăr et alii 2012a, 101

${ }^{4}$ Lazăr et alii 2012b, 109-110
} 
așezarea preistorică este cuprinsă între $44.891 \mathrm{~m}$ și $46.399 \mathrm{~m}$, date raportate la sistemul de proiecție al coordonatelor STEREO 70 și la sistemul de elevație Marea Neagră $1975^{5}$.

Această așezare preistorică este cunoscută în literatura de specialitate de mai multă vreme ${ }^{6}$, fără să fi fost însă investigată din punct de vedere arheologic. În condițiile unui proces de eroziune accelerat al terasei lacului Mostiștea datorită fenomenelor naturale, proces dublat de utilizarea zonei sitului ca groapă de împrumut de către localnici, începând cu anul 2008 s-au realizat mai multe sondaje de verificare în aşezarea de la Sultana-Ghețărie? ${ }^{7}$ Ulterior, începând cu anul 2012, s-a demarat o cercetare sistematică a acesteia ${ }^{8}$, care continuă și în prezent.

\section{DATE ARHEOLOGICE}

Cercetările de la Sultana-Ghețărie au condus la identificarea mai multor complexe tip groapă aparținând culturii Boian, faza Vidra. Acestora li se adaugă o serie de complexe atribuite unor perioade cronologice post-eneolitice (PI. II). De asemenea au mai fost investigate și patru morminte de inhumație, unul aparţinând comunităţilor Gumelnița (M1), iar celelalte trei (M2, M3 şi M4) fiiind atribuite secolelor VI-VIII p. Chr., pe baza elementelor de tratament funerar și vaselor ceramice descoperite în asociere cu scheletele respective?.

Majoritatea complexelor post-eneolitice reprezintă gropi moderne și contemporane (PI. II/1), realizate de către localnici pentru extragerea lutului. Doar complexul $\mathrm{Cl}$, pe baza materialelor ceramice și a datărilor ${ }^{14} \mathrm{C}$ poate fi atribuit culturii Cernavoda III (PI. IL/1).

Complexele atribuite culturii Boian, faza Vidra, cercetate până în prezent sunt în număr de şapte (PI. II/1). Majoritatea acestora reprezintă gropi de dimensiuni medii (C6, C8, C9, C13, C14, C22) sau mari (C20). Conținutul acestor complexe constă în materiale ceramice fragmentare, piese de silex, greutăți de lut, piese ce aparțin industriei materialelor dure animale (IMDA), bucăți de cărbune, pietre, scoici și oase de animale ${ }^{10}$.

Din punct de vedere al stratigrafiei verticale generale a sitului, situația complexelor arheologice cercetate în aşezarea de la Sultana-Ghețărie este relativ simplă. Astfel, nivelurile ce pot fi atribuite secvenței ocupaționale eneolitice sunt în număr de două: u.s. 1001 - un nivel ocupaţional surprins în toate secțiunile realizate și caracterizat printr-un sediment de culoare neagră, având textură relativ fină, cu fragmente de chirpici ars, piese de silex, ceramică şi puține oase în compoziție (prezintă amestecuri tipice de materiale caracteristice unui nivel de abandon); u.s. 1002 - un nivel ocupațional exterior surprins doar în anumite zone cercetate și caracterizat printr-un sediment de culoare galben-maron, textură fină, cu puține materiale arheologice, bucăți mari de loess pigmentate uneori cu carbonaţi. Pe alocuri apar numeroase perturbări datorate unor ganguri de animale, Acestea sunt suprapuse de nivelul vegetal (u.s. 1000), precum și de o depunere modernă (u.s. 999), rezultată din utilizarea zonei ca groapă de împrumut de către localnici ${ }^{11}$. De asemenea, în unele secțiuni, în urma procesului de săpare a suprafețelor arheologice s-a creat o unitatea stratigrafică nouă (u.s. 1034), rezultată în urma pământului excavat şi depus, dar şi a fenomenelor naturale anuale.

Nivelurilor ocupaționale atribuite comunităților Boian suprapun u.s. 1005, ce reprezintă un sediment de culoare galbenă, compact, relativ omogen, care conține numeroși carbonați şi foarte puţine materiale arheologice, fiind echivalentul u.s. T1003 din cadrul necropolei de la SultanaMalu Roșu, amplasată pe aceeași terasă. La baza secvenței stratigrafice de la Sultana-Ghețărie se găsește nivelul de loess (u.s. 1035), ce reprezintă ,sterilul arheologic”'2.

\footnotetext{
5 Lazăr et alii 2012a, 101

6 Serbănescu, Trohani 1978

Andreescu et alii 2009

${ }^{8}$ Andreescu et alii 2013

9 Lazăr et alii $2012 \mathrm{~b}$

${ }^{10}$ Nicolae et alii $2013 \mathrm{~b}$

${ }^{11}$ Nicolae et alii 2013a

${ }^{12}$ Lazăr et alii 2012b, 103
} 
În majoritatea cazurilor, complexele atribuite culturii Boian încep din u.s. 1002 și secționează u.s. 1005.

\section{CONTEXTUL DESCOPERIRII}

Suportul ce face obiectul studiului nostru a fost descoperit în complexul C13, din secțiunea S22, carourile 7-8. Acesta reprezintă o groapă cu formă relativ circulară (diametru $=1,70 \mathrm{~m})$, cu adâncime maximă de 0,91 m față de P0 (PI. III/1). Umplutura gropii (u.s. 1031), se caracterizează printr-un sediment de culoare galben-cenușie, afânat și eterogen, cu lentile de cenușă și de sol galben (probabil loess), precum și fragmente mici de cărbune, fiind foarte perturbat (bioturbații). Având în vedere caracteristicile acestei unităţi stratigrafice, dar și materialele arheologice identificate, se poate concluziona că există doar o singură secvență de umplere a gropii.

Din perspectivă stratigrafică, C13 începea din baza u.s. 1002, perforând u.s. 1005, baza sa aflându-se în u.s. 1035 (PI. III/2). Modul de relaționare al u.s.-lor este prezentat în diagrama stratigrafică (FIG. 1).

Inventarul gropii C13 consta în fragmente ceramice de la trei vase parțial întregibile vasul suport amintit, o „fructieră” (PI. V/2) și un vas tronconic cu pereți arcuiți spre exterior (PI. VI/1) și precum alte 23 de fragmente (PI. VI/2-3), oase de animale, scoici și pietre neprelucrate.

Suportul în discuție a fost descoperit în stare fragmentară (18 bucăţi), la baza gropii C13. Aceste fragmente nu erau grupate, fapt ce exclude ipoteza unei depuneri deliberate. Cel mai probabil respectivele bucăți de suport sunt rezultatul unei acțiuni de aruncare, care s-a produs concomitent cu celelalte materiale arheologice identificate.

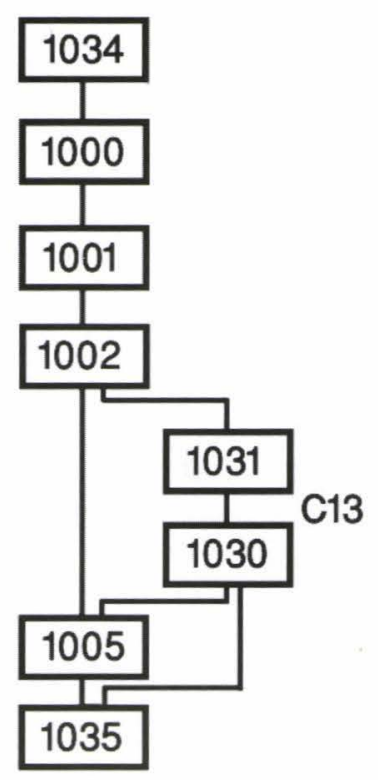

FIG. 1 DIAGRAMA STRATIGRAFICĂ A COMPLEXULUI C13 
Procesul de restaurare a suportului a constat în selectarea tuturor fragmentelor care păstrau caracteristici asemănătoare și pe care le-am considerat ca făcând parte din acest vas. Interesant este că toate fragmentele identificate s-au lipit între ele, formând un corp compact, cu o greutate de $1387 \mathrm{~g}$, ce reprezintă aproximativ $40 \%$ din vasul întreg (Pl. IV/1).

Restaurarea, parțială, ne-a permis să deducem dimensiunile suportului în discuție: L_inferioară $=260 \mathrm{~mm}, 1$ inferioară $=122 \mathrm{~mm}$, L_superioară $=230 \mathrm{~mm}, 1$ superioară $=114 \mathrm{~mm}$, h_max $=210 \mathrm{~mm}$. Deși, din punct de vedere tipologic, suportul în discuție face parte din categoria suporturilor de formă paralelipipedică ${ }^{13}$, ca formă geometrică acesta reprezintă un trunchi de piramidă patrulateră. Suportul a păstrat parțial unul dintre orificiile superioare cu un diametru de 80 $\mathrm{mm}$, precum şi un orificiu de formă neregulată pe unul din pereții laterali scurți.

Pasta din care a fost confecționat este de factură grosieră, cu cioburi pisate ce au servit drept degresant. Ridicarea pereților s-a realizat prin intermediul unor fâşii din lut dispuse orizontal. Urmele acestui procedeu pot fi observate pe latura lungă, cea mai bine reprezentată (Pl. IV/3). Partea superioară, placa cu cele două orificii, considerăm că a fost ultima adăugată. Starea de conservare nu ne permite să facem observații complete, însă există exemplare asemănătoare realizate în aceeași manieră ${ }^{14}$.

Toate suprafețele exterioare, inclusiv marginile orificiilor superioare (PI. IV/7), au fost lustruite intens, formându-se astfel o peliculă de lut fin de $0,50-1,00 \mathrm{~mm}$ grosime. Interiorul vasului a fost netezit neglijent, neuniform, probabil în timpul ridicării pereților. $O$ ultima intervenție la interior, în lutul încă moale, o constituie scrijelirea cu un obiect ascuțit a cărui amprentă încă poate fi observată (PI. IV/6).

Suprafețele exterioare, vizibile, au fost decorate, înainte de uscare, cu linii incizate pe pereții laterali și cu crestături pe toate cele patru muchii superioare. Liniile incizate de pe peretele lung, cel mai bine păstrat, au fost trasate orizontal. Acestea sunt grupate câte două, câte trei, iar în partea superioară apare o grupare de șapte linii, cu suprafețele „cruțate” între ele, aproximativ egale ca lățime (Pl. IV/3, Pl. V/1). Celălalt perete lung pare să păstreze doar în partea inferioară aceeași dispunere a liniilor incizate. Peretele scurt este decorat în partea inferioară cu trei perechi de câte două linii incizate, trasate orizontal la aceleași intervale, precum cele de pe pereții lungi, iar în partea superioară, în jurul orificiului, este realizat un decor meandric din linii incizate grupate câte două (PI. IV/2, Pl. V/1).

Arderea suportului s-a realizat într-o atmosferă neoxidantă ${ }^{15}$, rezultând astfel pereți de culoare neagră în toată secțiunea. Ultima etapă din procesul de realizare este reprezentată de umplerea liniilor incizate cu pastă albă, urmată de vopsirea suprafețelor lustruite, dintre grupările de incizii, cu pastă roșie. Banda lustruită din partea inferioară, precum și suprafața superioară din jurul orificiilor, nu au beneficiat de acest tratament.

Utilizarea intensă a vasului suport este atestată de urmele de uzură vizibile pe baza celor trei laturi păstrate (PI. IV/7). Un element care sugerează o posibilă funcționalitate este ilustrat de afumarea parțială a pereților interiori (PI. IV/4).

\section{DISCUṬII ȘI CONCLUZII}

Probabil, aspectul cel mai interesant al acestei categorii de suporturi îl reprezintă evoluția lor cronologică, limitată aproape exclusiv doar la comunitățile culturii Boian din cadrul fazelor finale (Vidra și Spanțov). Astfel, exceptând un suport de mari dimensiuni, cu patru orificii, decorat

\footnotetext{
${ }^{13}$ Comșa 1974, 109

${ }^{14}$ Cutia-suport întregită de la Vidra (Rosetti 1934, 15), identificată de către autorii prezentului articol în depozitul Muzeului Municipiului București, este construită în maniera amintită.

${ }^{15}$ PCRG 2010, 29
} 
cu benzi verticale lustruite/scrijelite şi linii incizate cu pasta albă încrustată sub marginea superioară, provenit din nivelul Gumelniţa Al din aşezarea de tip tell de la Vlădiceasca ${ }^{16}$, restul descoperirilor de acest tip sunt atribuite secvenței crono-culturale sus menționate.

Primele suporturi de acest tip au fost descoperite în cadrul așezării de tip tell de la Vidra, în cadrul nivelelor atribuite culturii Boian ${ }^{17}$. Ulterior, piese complete sau fragmentare din această categorie sunt amintite în aşezările de la Boian A - Grădiştea Ulmilor ${ }^{18}$, Glina ${ }^{19}$, Radovanu ${ }^{20}$, Spanțov $^{21}$, Tangâru ${ }^{22}$ sau Vlădiceasca ${ }^{23}$.

Suportul descoperit la Sultana-Ghețărie se încadrează tipologic în seria celorlalte piese de acest tip şi completează spectrul informațional legat de această categorie de artefacte specifice comunităților Boian. Analiza tehnologico-funcțională realizată privitor la această piesă aduce date noi privind modul de manufacturare al suporturilor paralelipipedice. În viitor, pe baza datelor decelate din această analiză, avem intenția de a verifica modul de realizare şi funcționalitatea acestui tip de suport în cadrul programului de arheologie experimentală ce se desfăşoară anual la Sultana.

Observăm că forma nu este singura caracteristică constantă a acestor suporturi. Decorarea suprafețelor exterioare cu linii incizate umplute cu pastă albă şi pictarea cu roşu crud sunt elemente definitorii ${ }^{24}$ pentru majoritatea suporturilor de acest tip, inclusiv pentru cel descoperit la SultanaGhețărie. În opinia unor autori, această practică de pictare bicromă (cu alb şi roșu) trebuie pusă în legătură cu ritualuri de mediere între lumea viilor și lumea morților ${ }^{25}$. Totuși, având în vedere faptul că piesa în discuție provine dintr-un context domestic şi nu unul funerar, această interpretare are valoare de ipoteză de lucru. Prezența urmelor de afumare la interior ${ }^{26}$ (PI. IV/4), precum și descoperirea unor exemplare în apropierea vetrelor ${ }^{27}$, ar putea indica utilizarea acestor suporturi în asociere cu focul.

$\mathrm{Nu}$ în ultimul rând, frecvența redusă a acestor suporturi în diverse contexte arheologice atestă indirect utilizarea lor restrânsă, probabil rezervată exclusiv unor persoane cu statut special din cadrul grupului social sau poate unor evenimente deosebite din cadrul comunităților respective. Evident, această interpretare are doar caracter de ipoteză de lucru, mai ales datorită absenței unei analize exhaustive a tuturor suporturilor de acest tip din România și Bulgaria.

Pe baza datelor disponibile este dificil de afirmat ce anume susțineau aceste suporturi şi dacă într-adevăr funcția lor primară era aceea de suport. Ipotezele formulate până acum ${ }^{28}$ pot fí plauzibile, însă nu există suficiente argumente pentru a ne pronunța categoric în favoarea uneia sau alteia dintre acestea.

Fragmentele suportului din groapa $\mathrm{C} 13$ au fost descoperite împreună cu fragmente ceramice ce s-au întregit parțial. Acestea aparțin unui vas cu picior, atent decorat cu excizii încrustate cu pastă albă (Pl. V/2) și un vas tronconic cu pereți arcuiți spre exterior, cu urme de procesare a unor substanțe organice prin expunere la foc (PI. VI/1), toate fiind situate în partea inferioară a umpluturii (u.s. 1031). Lentilele de cenușă şi fragmentele mici de cărbune erau omniprezente printre resturile vaselor amintite. Toate aceste „resturi” credem că reflectă gestul final al unei expresii sociale/cultice ce ar fi implicat utilizarea focului, a unui vas comun ce a servit la procesare/gătire, a unei „fructiere” cu proprietăți ce o recomandă consumului colectiv şi a unui vas suport ce nu se afla la prima utilizare ${ }^{29}$, dar cu siguranță la ultima.

\footnotetext{
${ }^{16}$ Şerbănescu 2014

${ }^{17}$ Rosetti 1934

${ }^{18}$ Comșa 1959, 127

${ }_{19}^{19}$ Petrescu-Dâmbovița 1944, 70

${ }^{20}$ Comșa 1990, 56

${ }^{21}$ Morintz, Preda 1959, 164-165

22 Berciu 1935, 13

${ }^{23}$ Şerbănescu, Şandric 2012, 117; Șerbănescu 2013, 2014

${ }^{24}$ Rosetti 1934, 13; Comşa 1974, 119; Șerbănescu, Şandric 2012, 117

${ }^{25}$ Dragoman 2013,99

${ }^{26}$ Rosetti 1934, 13; Berciu 1935, 13

${ }^{27}$ Berciu 1935, 13; Berciu 1937, 45-46

${ }^{28}$ Suporturi pentru vase cu baza conică (Rosetti 1934, 13), suporturi pentru vase cu picior de tip Steckdose (PetrescuDâmbovița 1944, 70; Comşa 1974, 109) sau modele de locuințe (Rosetti 1934, 13; Comşa 1974, 119)

${ }^{29}$ Conform urmelor de uzură de pe bază.
} 
Avem speranța că viitoare cercetări arheologice de la Sultana-Ghețărie să conducă la descoperirea de noi suporturi de acest tip ${ }^{30}$, care să ne permită alte observații legate de această categorie de piese deosebite.

\section{MULȚUMIRI}

Această notă a fost realizată în cadrul programului POSDRU/159/1.5/S/137832 „MINERVA - Cooperare pentru cariera de elită în cercetarea doctorală și post-doctorală" și a programului Parteneriate in domenii prioritare - PN II, derulat cu sprijinul MEN - UEFISCDI, proiect nr. 338/2014.

Dorim să mulțumim colegilor Adrian Bălăşescu pentru lecturarea textului şi sugestiile făcute, precum și Ionelei Crăciunescu pentru prelucrarea planurilor privind situl Sultana-Ghețărie. În final, dorim să mulțumim și celorlalți membri ai echipei de cercetare ce au participat la săpăturile din acest sit în intervalul 2012-2014, în special colegilor Theodor Ignat, Cătălin Nicolae, Mihai Florea, Mădălina Voicu, Mihaela Golea, Adelina Darie, Laura Șendrea, Radu Bălănescu, Cristian Caravană şi Ciprian Crețu.

BIBILIOGRAFIE

Andreescu et alii 2009

Andreescu et alii 2013

Berciu 1935

Berciu 1937

Comșa 1959

Comşa 1974

Comşa 1990

Dragoman 2013

Lazăr et alii 2012a

Lazăr et alii 2012b

Morintz, Preda 1959

Nicolae et alii 2013a
R. Andreescu, C. Lazăr, M. Florea, Katia Moldoveanu, T. Ignat, Alexandra Ion, A. Soficaru, A. Bălăşescu, V. Radu, M. Chiţonu, Sultana, com. Mânăstirea, jud. Călăraşi, Punct: Malu Roşu, $C C A, 2009$, p. 205207

R. Andreescu, C. Lazăr, M. Florea, V. Opriș, Mădălina Voicu, C. Haită, V. Radu, G. Vasile, A. Bălășescu, T. Ignat, C. Nicolae, Mihaela Golea, Laura Şendrea, Mihaela Danu, V. Parnic, M. Neagu, Sultana, com. Mânăstirea, jud. Călărași, Punct: Malu Roșu, $C C A$, 2013, p. 123-124

D. Berciu, Săpăturile arheologice de la Tangâru (1934), Raport preliminar, Buletinul Muzeului Judetean Vlaşca, I, 1935, p. 1-55

D. Berciu, Prime considerațiuni asupra neoliticului din Valea Dunării inferioare în legătură cu descoperirile din județul Vlașca, Buletinul Muzeului Judetean Vlașca, II, București, 1937, p. 31-105

E. Comşa, Săpături arheologice la Boian-Grădiştea Ulmilor, $M C A$, VI, 1959, p. $127-135$

E. Comşa, Istoria comunitătilor culturii Boian, București, 1974

E. Comşa, Complexul neolitic de la Radovanu, $C C D J$, VIII, 1990, p. 7126

R.-A. Dragoman, O biografie a ceramicii neolitice de la Vădastra, Bucureşti, 2013

C. Lazăr, Mădălina Voicu, G. Vasile, Traditions, Rules and Exceptions in the Eneolithic Cemetery from Sultana-Malu Roşu (Southeast Romania), în Raluca Kogălniceanu, Roxana Curcă, M. Gligor, Susan Stratton (eds.), Homines, Funera, Astra. Proceedings of the International Symposium on Funerary Anthropology, 5-8 June 2011, I Decembrie 1918' University (Alba Iulia, Romania), BAR, International Studies, no. 2410, Oxford, 2012, p. 107-118.

C. Lazăr, G. Vasile, Monica Mărgărit, Some considerations about a new grave discovered at Sultana-Ghețărie (Southeastern Romania), SP, 9, 2012, p. 101-111

S. Morintz, C. Preda, Săpăturile dela Spanțov, $M C A$, V, 1959, p. 163-173

C. Nicolae, Mihaela Golea, M. Florea, C. Lazăr, Așezarea Boian de la Sultana - Ghețărie. Rezultatele Campaniei 2012, comunicare susținuta la

${ }^{30}$ Sau măcar restul de $60 \%$ din suportul deja descoperit în groapa $\mathrm{C} 13$. 
Nicolae et alii $2013 b$

PCRG 2010

Petrescu-Dâmbovița 1944

Rosetti 1934

Şerbănescu 2013

Serbănescu 2014

Şerbănescu,Trohani 1978

Şerbănescu, Şandric 2012
Sesiunea Anuală de Comunicări Ştiinţifice a Institutului de Arheologie „Vasile Pârvan” al Academiei Române, 27-29.03.2013, Bucureşti

C. Nicolae, C. Lazăr, Mădălina Voicu, M. Florea, Considerații privind locuirile culturii Boian de pe Valea Mostiștei. Așezarea de la SultanaGhețărie, jud. Călăraşi, comunicare susținuta la a XLVI Sesiunea Științifica Internaționala Pontica, Octombrie 2013, Constanța

Prehistoric Ceramics Research Group, The Study of Prehistoric Pottery: General Policies and Guidelines for Analysis and Publication, Occasional Papers, nos. 1 and 2, 2010

M. Petrescu-Dâmbovița, Raport asupra săpăturilor de la Glina, jud. Ilfov, 1943, Raport asupra activitătii știintifice a Muzeului National de Antichităti în anii 1942 și 1943, București, 1944, p. 65-71

D.V. Rosetti, Săpăturile de la Vidra - raport preliminar, Publicatiile Muzeului Municipiului București, 1, 1934, p. 6-65

D. Şerbănescu, Research on the Eneolithic tell of Vladiceasca, Călărași County - Romania, în Alexandra Comșa (ed.), Facets of the Past, The Challenge of the Balkan Neo-Eneolithic, Proceedings ot the International Symposium Celebrating the $85^{\text {th }}$ Birth Anniversary of Eugen Comșa, 6-12 October, 2008, Bucharest, Romania, București, 2013, p. 312-335

D. Șerbănescu, Ceramica Gumelnița Al. Studiu de caz tell-ul Vlădiceasca, jud. Călărași, comunicare orală, Sesiunea Internatională de Comunicări Pontica XLVII, 2-3 octombrie, Constanța, 2014

D. Şerbănescu, G. Trohani, Cercetările arheologice pe Valea Mostiștea, în Ilfov, 1978, p. 18-32

D. Şerbănescu, B. Şandric, Tell-uri eneolitice în regiunea Valea Mostiştei. O privire generală, în A.S. Morintz, Raluca Kogălniceanu (eds.), Survey in Archaeology, often a neglected science, Proceedings of the II Archaeological Symposium, Giurgiu, October $23^{\text {rd }}-26^{\text {th }}, 2011$, Archaeological Debates, 2, 2012, p. 103-150

LIST OF ILLUSTRATION

Pl. I. 1. Geographic location of the Sultana-Ghețărie site; 2. Distribution of the settlements and necropolises in the area of Sultana site

Pl. II. 1. Layout of the archaeological complexes researched at Sultana-Ghețărie (2012-2014); 2. Ground plan of complex $13 ; 3$. Westem cross-section profile of complex 13

Pl. III. Stratigraphic diagrame of complex 13.

Pl. IV. The pot stand from pit C13: 1. After restauration; 2. The short side; 3. The long side; 4. Traces of smoke on the interior; 5 . Traces of wear on the base; 6 . Impression of a vegetal fiber, inside the vessel; 7 . The upper orifice (upper norm)

Pl. V. 1. Graphic reconstruction of the shape and decoration; 2. The stem vessel of the pit C13 (after restauration)

Pl. VI. The pit C13: 1. The bowl type vessel after restauration; 2. Pottery shred with excised decor; 3. Grounded shreds in a pottery fragment; 4. Pottery fragment decorated with barbotine.

VASILE OPRIS

Muzeul Municipiului București vasilelieopris@yahoo.com

CĀTĀLIN LAZĀR

Muzeul Național de Istorie a României lazarc@arheologie.ro 



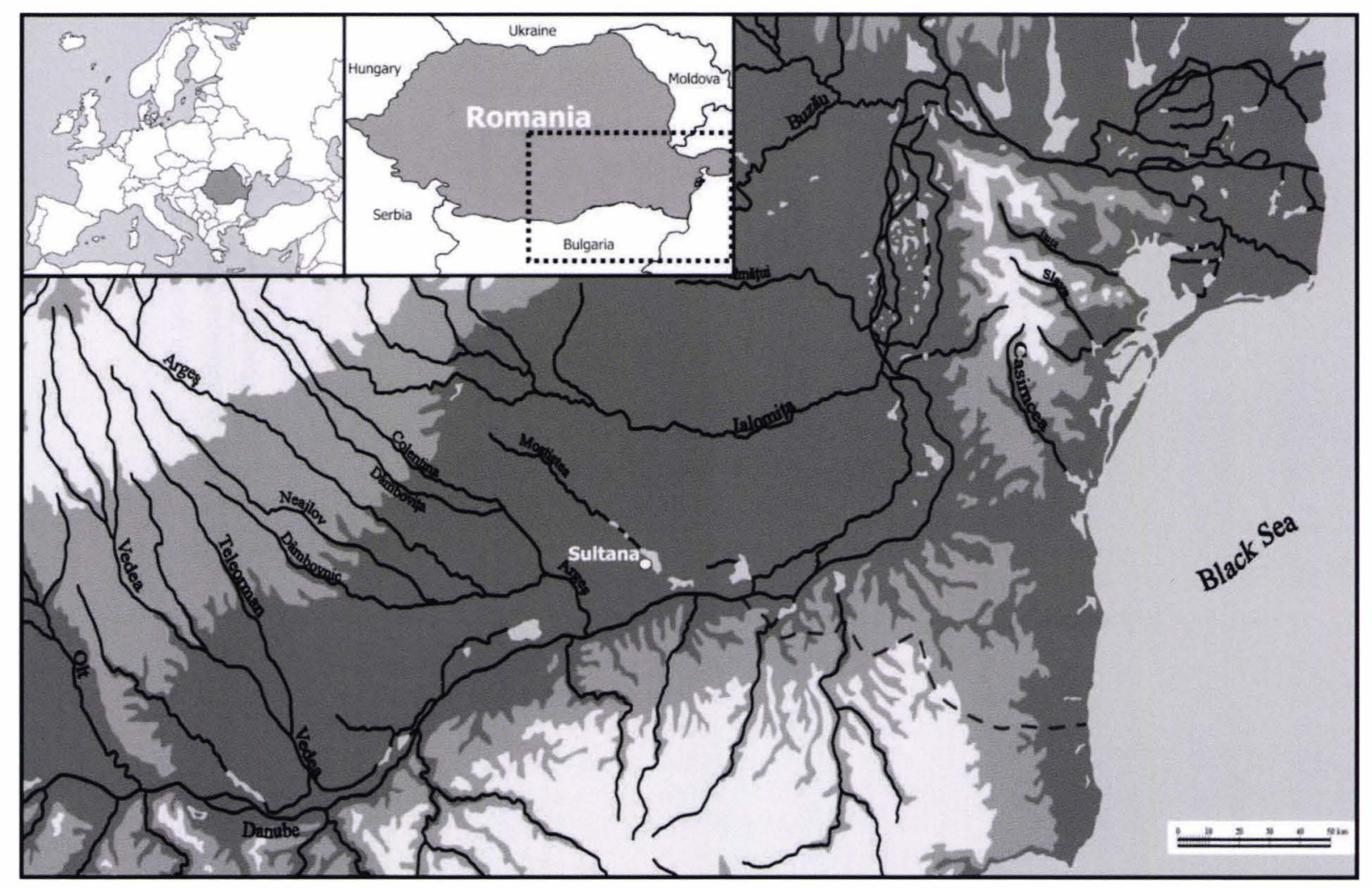

1.

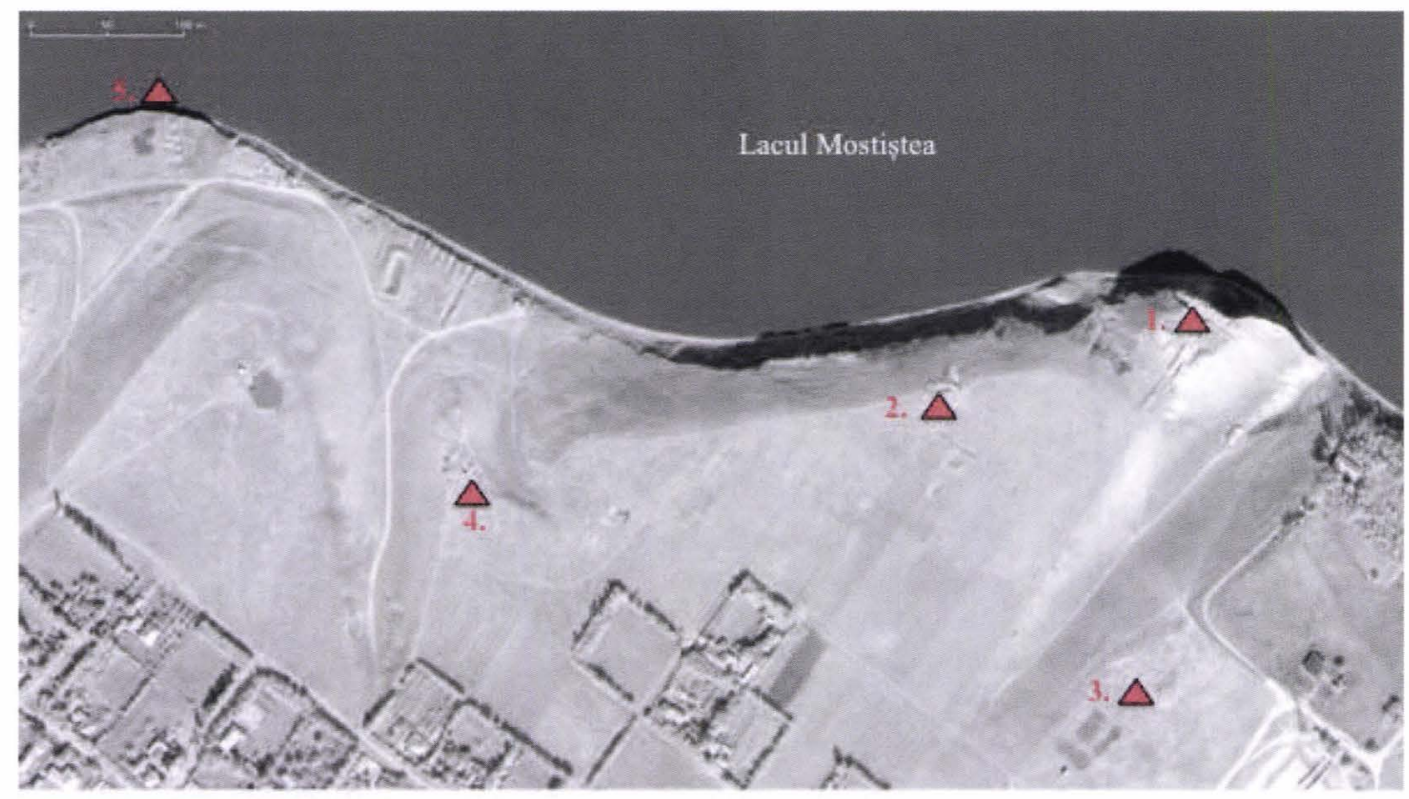

\section{A Assezarea tip tell \\ 2. A Necropola I \\ 3. $\Delta$ Necropola II \\ 4. A Așezarea comunităților Boian}

5. A Necropola III

2.

1. Localizarea geografică a sitului Sultana-Ghețărie; 2. Distribuția așezărilor și necropolelor din zona sitului Sultana 


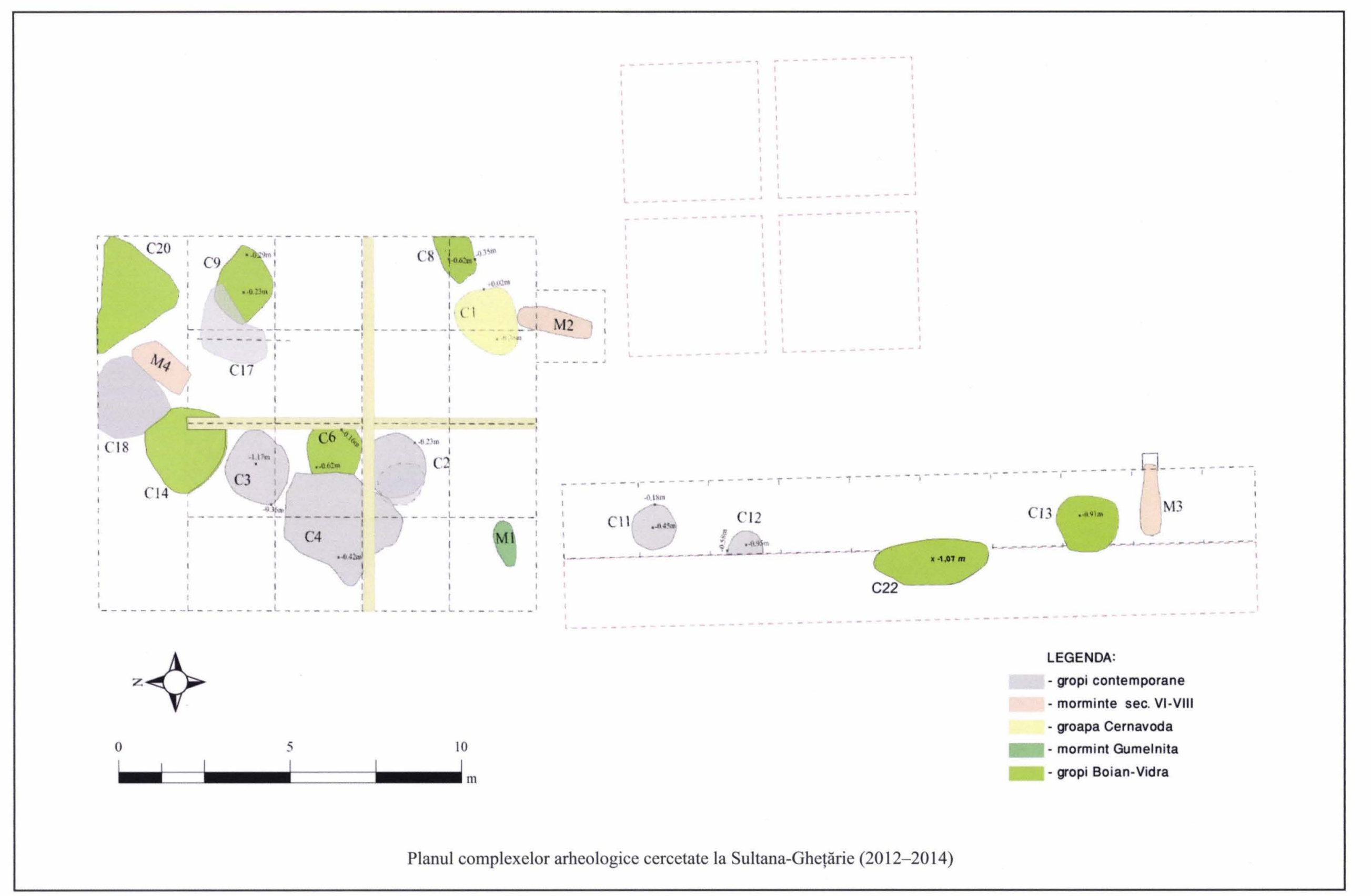

\section{PI. II}




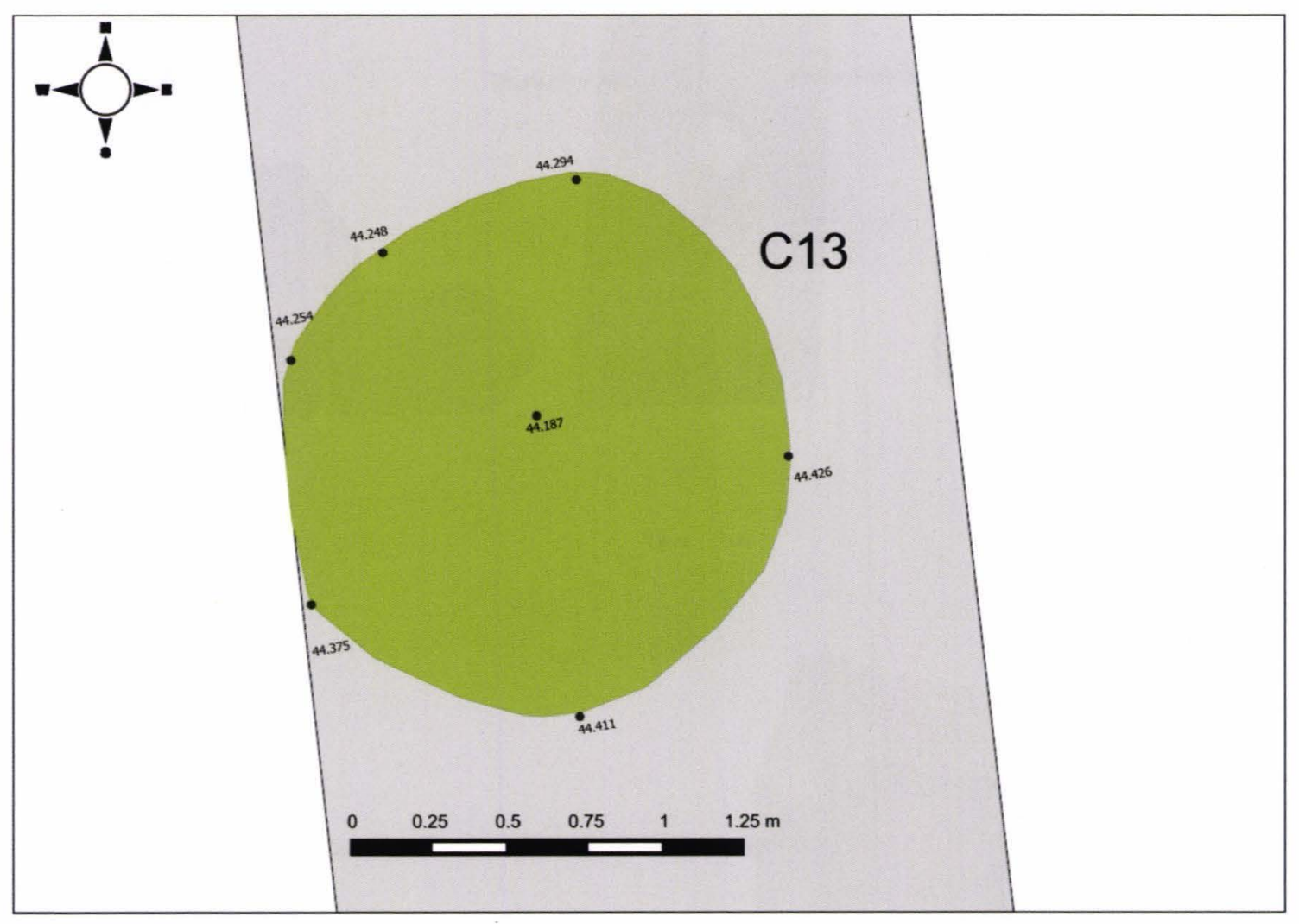

1.

$\stackrel{s}{\longleftarrow}$

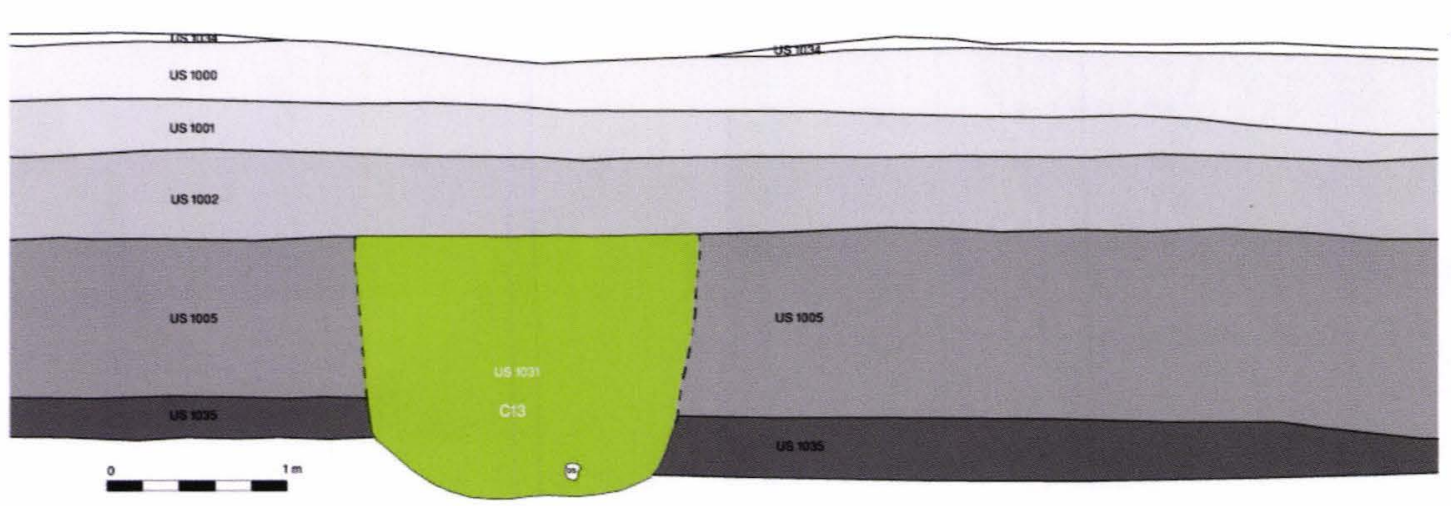

2.

Complexului C13: 1. Plan; 2. Profilul vestic 


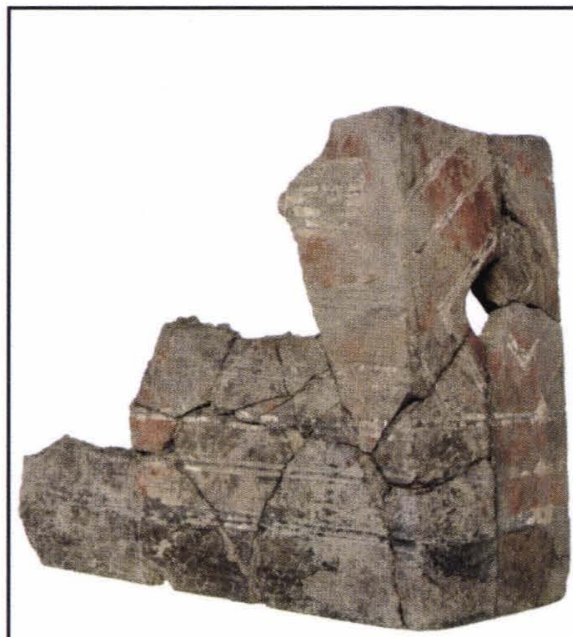

1.

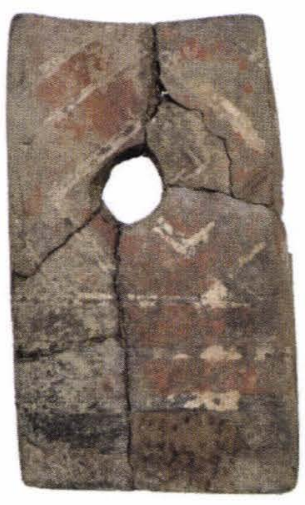

2.

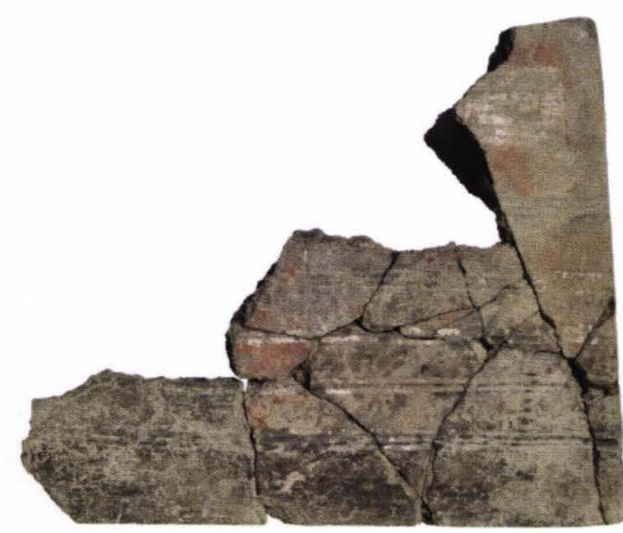

3.

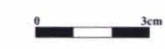

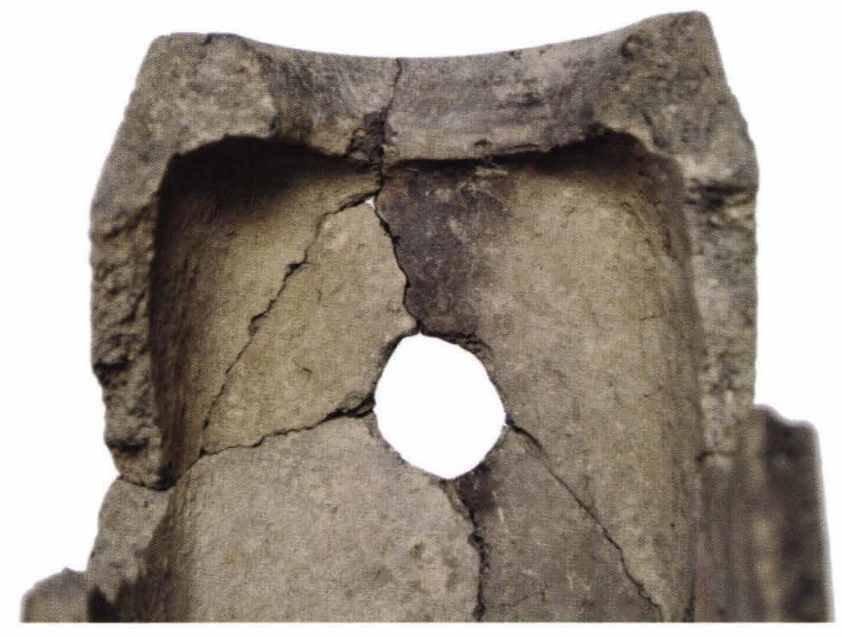

4.

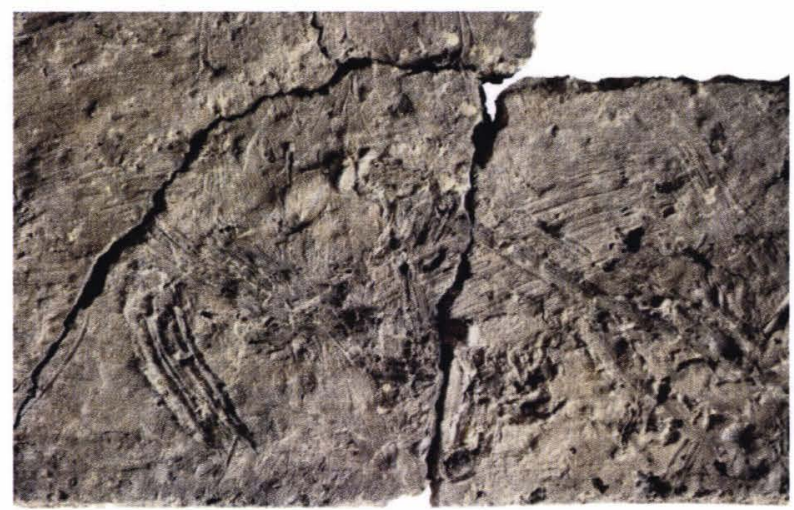

6.

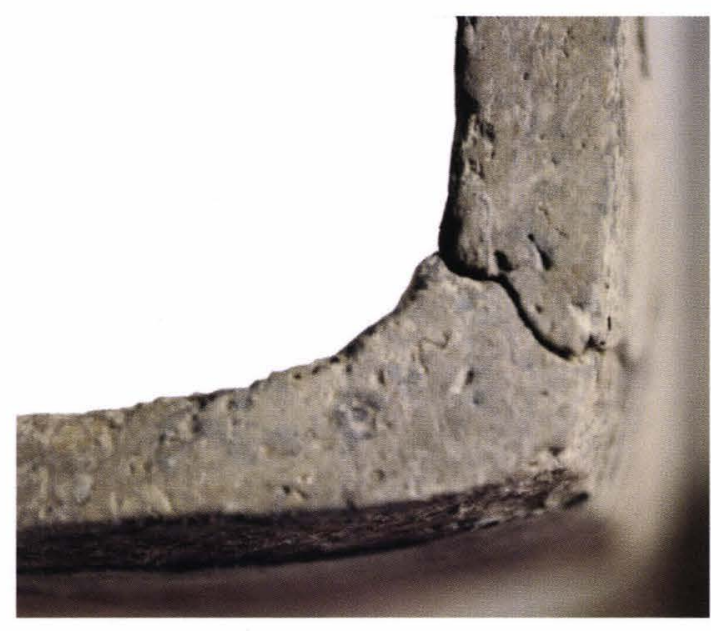

5.

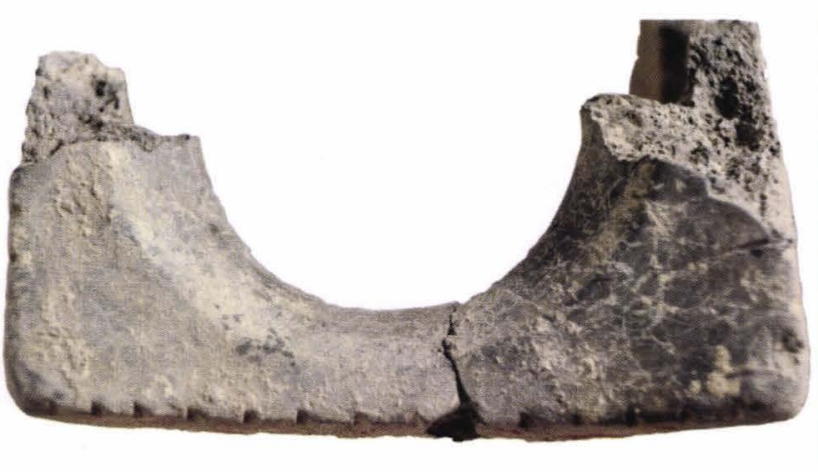

7.

Vasul suport din groapa C13: 1. După restaurare; 2. Peretele scurt; 3. Peretele lung; 4. Urme de afumare la interior; 5. Urme de uzură pe bază; 6 . Amprentele unei fibre vegetale, la interior; 7. Orificiul superior (normă superioară) 

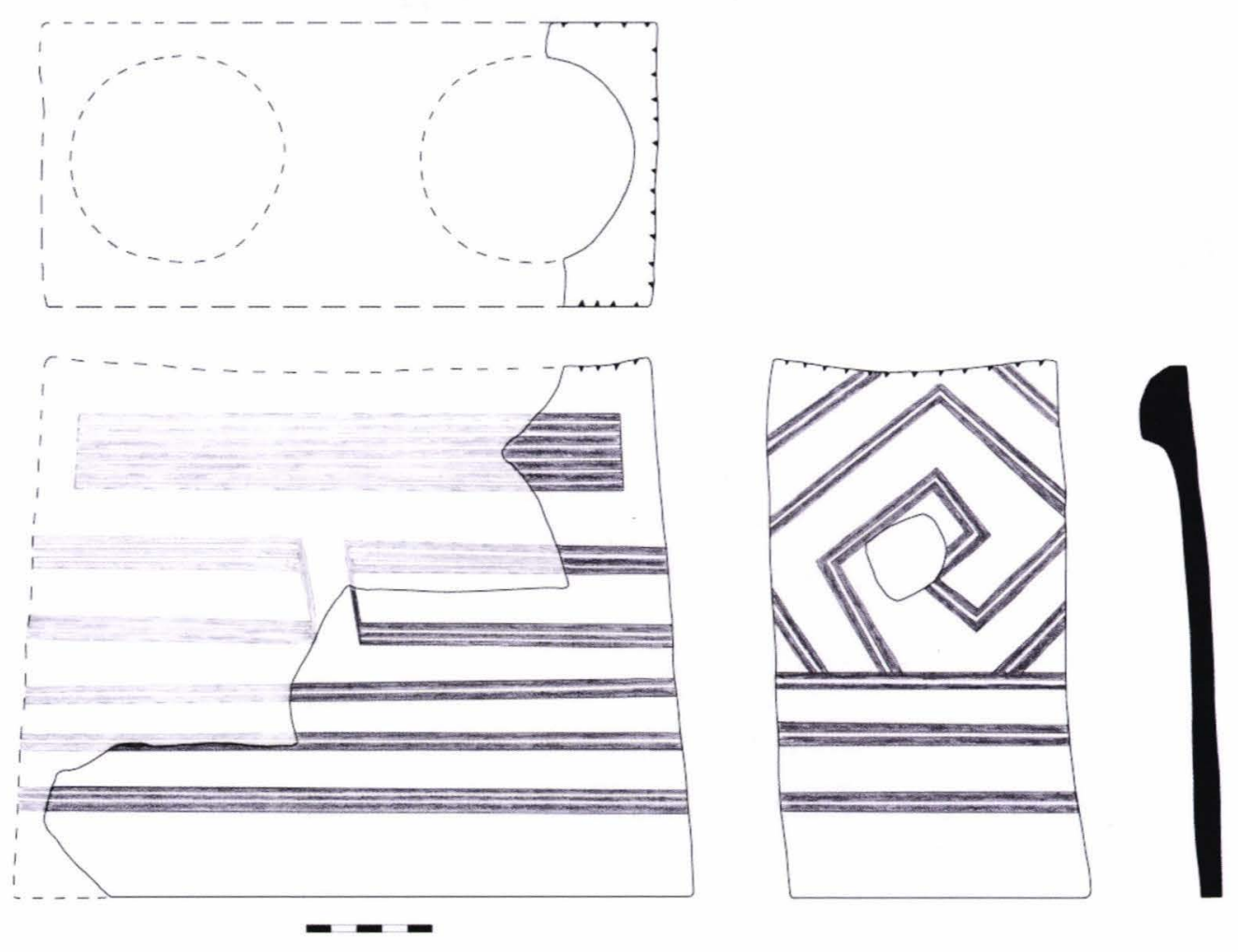

1.
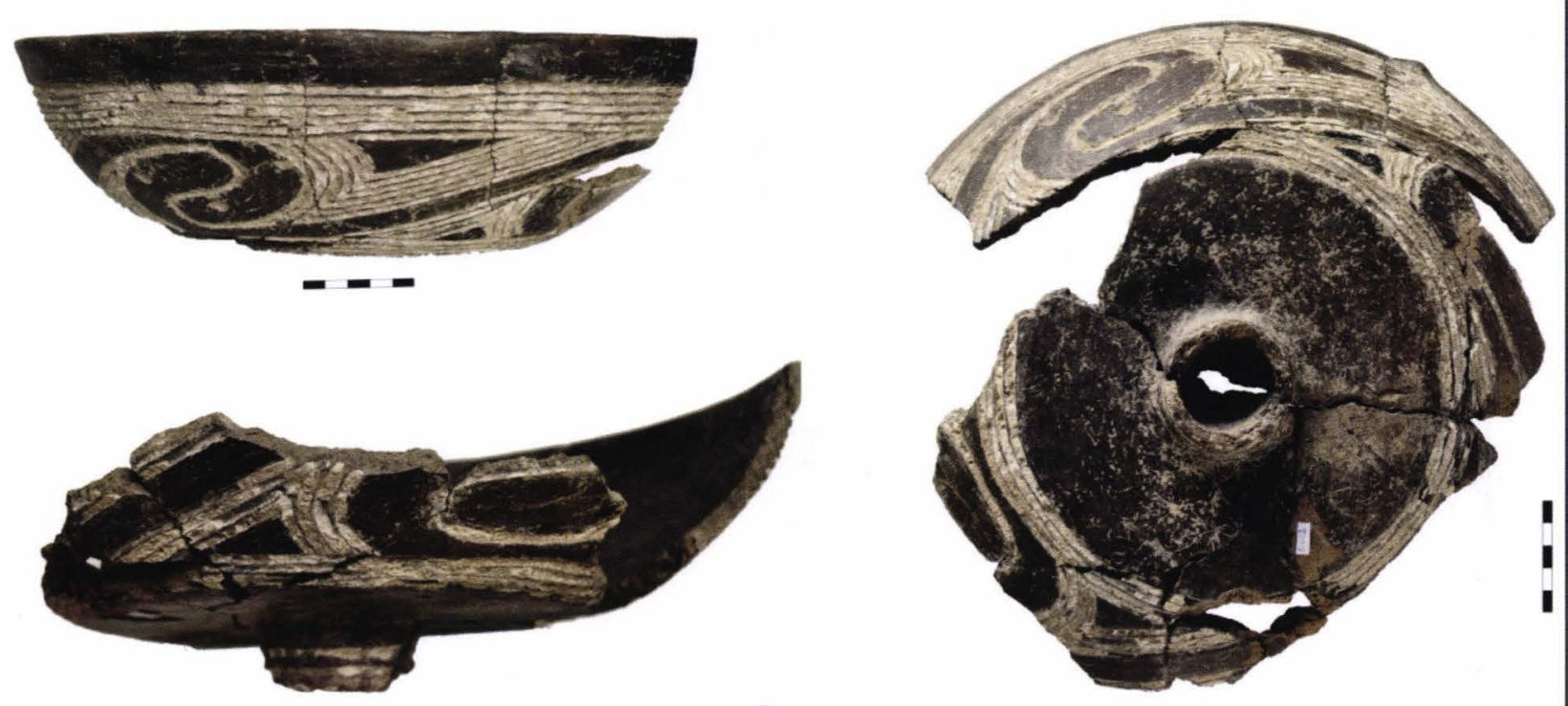

2.

1. Reconstituire grafică a formei şi a decorului; 2. Vasul cu picior, din groapa C13 (după restaurare) 

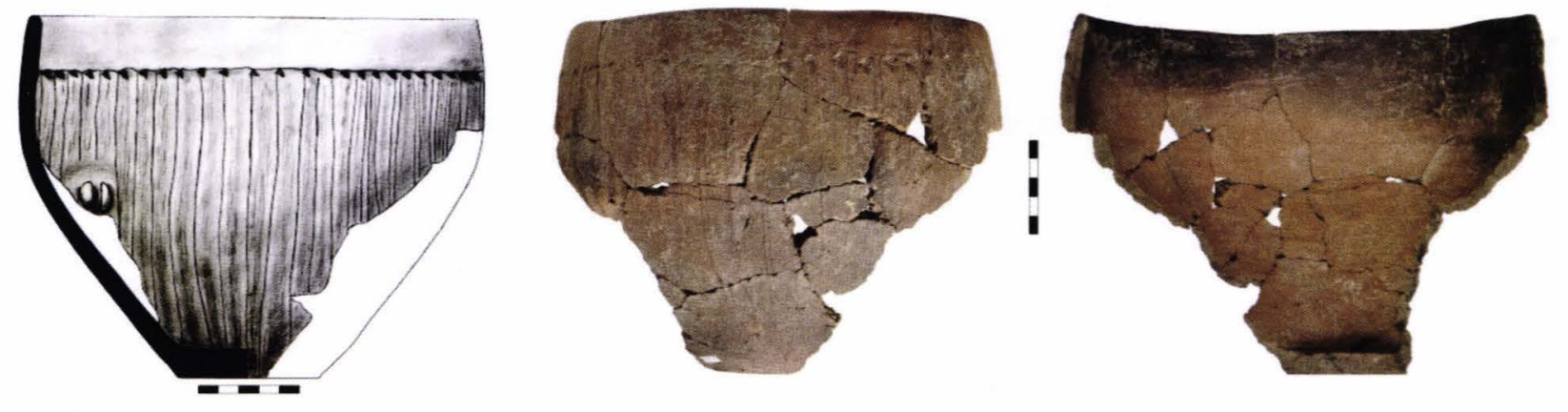

1.

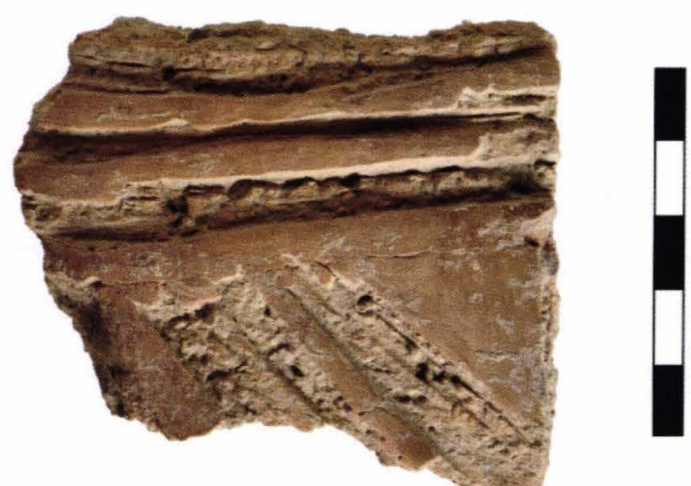

2.

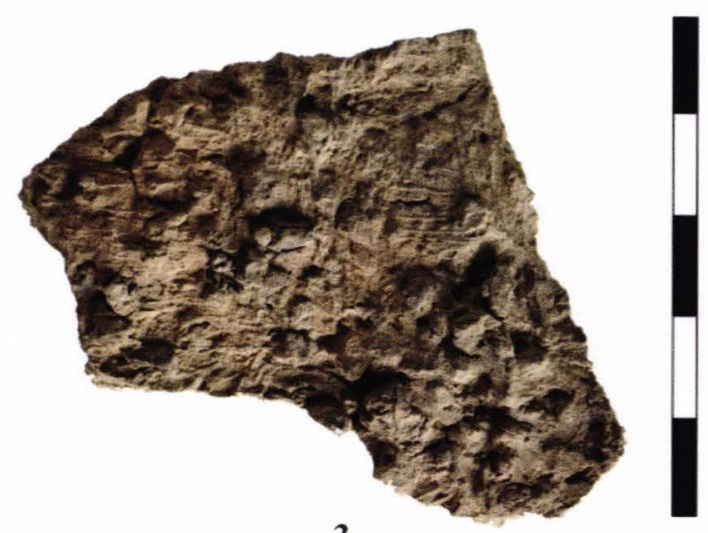

3.

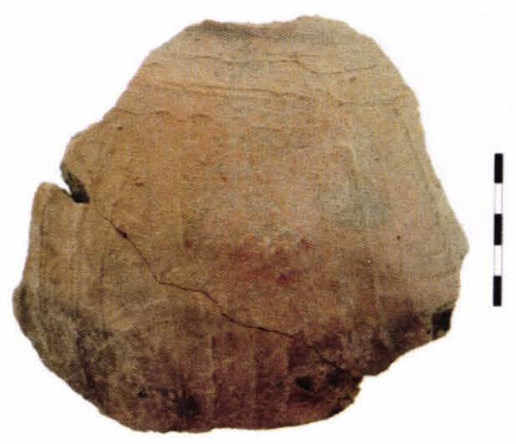

4.

Groapa C13: 1. Vasul de tip castron (după restaurare); 2. Fragment ceramic cu decor excizat; 3. Cioburi pisate într-un fragment ceramic; 4. Fragment ceramic decorat cu barbotină 